\title{
Comparison of essential oil compositions of fresh and dried fruits of Magnolia kobus DC.
}

\author{
Kandhasamy Sowndhararajan, Haeme Cho, Byoungsun Yu, Songmun Kim* \\ Department of Biological Environment, Kangwon National University, Chuncheon 24341, Republic of Korea.
}

\begin{tabular}{|c|c|}
\hline ARTICLE INFO & ABSTRACT \\
\hline Article history: & The aim of this work was to determine the volatile constituents of fresh and dried (shade dried) fruits of \\
\hline Received on: $30 / 12 / 2015$ & Magnolia kobus DC. using gas chromatography-mass spectrometry (GC-MS). Essential oils from fresh and dried \\
\hline Revised on: 18/01/2016 & fruits of M. kobus were obtained by steam distillation and the yields were 0.81 and $1.73 \%(\mathrm{v} / \mathrm{w})$, respectively. \\
\hline Accepted on: 01/02/2016 & GC-MS analysis revealed the identification of seventeen components from both the fresh and dried fruits of $M$. \\
\hline Available online: $30 / 04 / 2016$ & kobus, which were mostly monoterpene hydrocarbons (62.8-71.8\%). A comparison of oils from fresh and dried \\
\hline $\begin{array}{l}\text { Key words: } \\
\text { Magnolia kobus, essential } \\
\text { oil, fruit, dried. }\end{array}$ & $\begin{array}{l}\text { pinene }(26.7-31.6 \%), \beta \text {-pinene }(20.2-27.9 \%) \text { and limonene }(8.6-10.0 \%) \text {. In the dried sample, concentration of } \alpha \text { - } \\
\text { pinene, } \beta \text {-pinene, caryophyllene, camphene, and } \alpha \text {-humulene contents were decreased. On the other hand, } \\
\text { limonene, } \alpha \text {-terpineol, bornyl acetate and terpinen-4-ol contents were increased in the dried sample. The present } \\
\text { investigation clearly suggested that the drying treatment decreased the concentration of major components in the } \\
\text { essential oil of } M . \text { kobus fruit. }\end{array}$ \\
\hline
\end{tabular}

\section{INTRODUCTION}

Magnoliaceae is one of the families of flowering plants and the genus Magnolia contains more than 128 species, with about two-thirds of species are distributed in East and Southeast Asia (Azuma et al., 1999; Gottsberger et al., 2012). Flower buds of different Magnolia species have been used for the treatments of nasal congestion with headache, sinusitis and allergic rhinitis (Jung et al., 1998; Kim et al., 2003). Kobayashi et al. (1998) also studied the antirheumatic and antiangiogenic activities of Magnolia flower.

Previous studies have reported that the essential oil from different parts of Magnolia taxa have a very wide distribution of monoterpenoid and sesquiterpenoid components (Barros et al., 2012; Guerra-Boone et al., 2013). Magnolia kobus DC is a medium sized deciduous tree native to Japan, also distributed in China and Korea. Flower buds of M. kobus are essential ingredients in the Chinese traditional medicine 'Shin-I', which is used for the treatments of headaches, and colds (Matsutani and Shiba, 1975). Previous chemical studies on M. kobus showed that it to be a source of bioactive terpenes and

* Corresponding Author

Songmun Kim, Department of Biological Environment, Kangwon

National University, Chuncheon 24341, Republic of Korea

Email:perfume[at]kangwon.ac.kr lignans (Seo et al., 2008). However, there is no information available on the essential oil composition of M. kobus fruit. Medicinal plants can be marketed as fresh or dried products depending on their use and consumer's preference. Fresh herbs cannot be distributed in a profitable way to world-wide because they contain about $75-80 \%$ of water. So, it is essential to lower the water levels to less than $15 \%$ for the preservation of plant materials (Diaz-Maroto et al., 2002a, 2002b). Drying is the most widely used preservation method to obtain high quality products. Previous studies have reported that drying processes inhibit the microbial growth, extend the shelf life of product, minimize packaging requirements and reduce shipping weights (Hossain et al., 2010; Hamrouni-Sellami et al., 2012; Kubra and Rao, 2012). Further, the drying processes minimize the loss of active components and delay their biological deterioration by reducing enzymatic activities. Dehydration of herbal plants can be achieved using different methods. In the various drying methods, natural drying (under shade) and hot air drying are the inexpensive and most commonly used methods (Soysal, 2004). The quality of volatile components in the aromatic plants is mainly depends on drying methods and biological characteristics of the plant species (Venskutonis, 1997). The essential oil components are more sensitive to drying process. Hence, it is more essential to understand the changes in the volatile oils from fresh and dried fruits of M. kobus in determining the potential of this oil for commercial utilization. 
The aim of this study was to compare the volatile oil compositions of fresh and dried (shade dried) fruits of M. kobus.

\section{MATERIALS AND METHODS}

\section{Plant material}

Fruits (unripen) of Magnolia kobus DC. were collected from Chuncheon, Gangwon province, Korea during the month of August 2013. The plant was authenticated and deposited in the Herbarium, Kangwon National University with voucher number KWNU 71688.

\section{Extraction of essential oil}

For the comparison of essential oil composition of fresh and dried fruits, a portion of the fresh fruits was extracted and analyzed immediately and equal portion of fruits dried under shade at $25 \pm 2{ }^{\circ} \mathrm{C}$ for 1 week, then extracted and analyzed. The volatile oil was isolated by steam distillation ( $1 \mathrm{~kg}$ fruits) for $1 \mathrm{~h}$. The lighter than water, slightly yellow oils were dried over anhydrous $\mathrm{Na}_{2} \mathrm{SO}_{4}$ and stored under refrigeration $\left(+4{ }^{\circ} \mathrm{C}\right)$. Oil yields were determined on an oven-dry weight basis $\left(48 \mathrm{~h}\right.$ in $\left.65^{\circ} \mathrm{C}\right)$.

\section{Chemical composition of essential oil}

GC-MS analysis was performed with a Varian CP3800 gas chromatography equipped with a VF-5MS polydimethylsiloxane capillary column $(30 \times 0.25 \mathrm{~mm} \times 0.25 \mu \mathrm{m})$ and a Varian 1200L mass detector (Varian, CA, USA). Helium was used as a carrier gas at the rate of $1 \mathrm{~mL} / \mathrm{min}$. Oven temperature was kept at $50{ }^{\circ} \mathrm{C}$ for $5 \mathrm{~min}$ initially, and then raised with rate of $5^{\circ} \mathrm{C}$ min to $250{ }^{\circ} \mathrm{C}$. The injected volume of essential oil was $10 \mu \mathrm{L}$ with a split ratio of $1: 10$. The injector temperature was set at $250{ }^{\circ} \mathrm{C}$. The mass spectra were recorded in the electrospray ionization mode at $70 \mathrm{eV}$ in a scan range of $50-600$ $\mathrm{m} / \mathrm{z}$.

\section{Identification of components}

The components of the volatile oils from fresh and dried samples were identified by comparison of their retention indices to n-alkanes $\left(\mathrm{C}_{9}-\mathrm{C}_{18}\right)$ and their mass spectral fragmentation pattern with those reported in the literature (Adams, 2007), and stored in the MS libraries (Wiley 275 and National Institute of Standards and Technology (NIST, 3.0) ${ }^{20}$.

\section{RESULTS AND DISCUSSION}

The volatile oils were isolated from fresh and dried fruits of M. kobus by steam distillation. The higher oil yield was obtained from dried fruits $(1.73 \pm 0.21 \%)$ followed by fresh fruits $(0.81 \pm 0.04 \%)$ on a dry weight basis. The chemical composition of fresh and dry fruits of $M$. kobus was determined using GC-MS techniques. The fresh fruits of $M$. kobus revealed the separation of 12 different compounds. Whereas, essential oil obtained from dry fruits of $M$. kobus revealed the detection of 16 different components. The area percentage and retention indices of the identified compounds are presented in Table 1. The fresh and dried fruits contained complex mixture consisting mainly by monoterpene hydrocarbons (62.8-71.8\%), sesquiterpene hydrocarbons (5.9-10.9\%), oxygenated monoterpenes (8.9$13.2 \%)$ and oxygenated sesquiterpenes $(5.7-8.3 \%)$ (Fig. 1). A comparison of oils from fresh and dried fruits revealed the changes in the amounts of several constituents, especially in mono- and sesquiterpene hydrocarbons. $\alpha$-Pinene (26.7-31.6\%) was the most abundant component followed by $\beta$-pinene $(20.2-27.9 \%)$ and limonene (8.6-10.0\%) in both the fresh and dried fruits of $M$. kobus. Other quantitatively important components were $\alpha$ terpineol (3.2-4.8\%), caryophyllene (3.9-8.1\%), camphene (3.3$3.7 \%)$, bornyl acetate (1.7-3.2), eucalyptol (2.9\%), $\alpha$-humulene $(2.0-2.8)$.

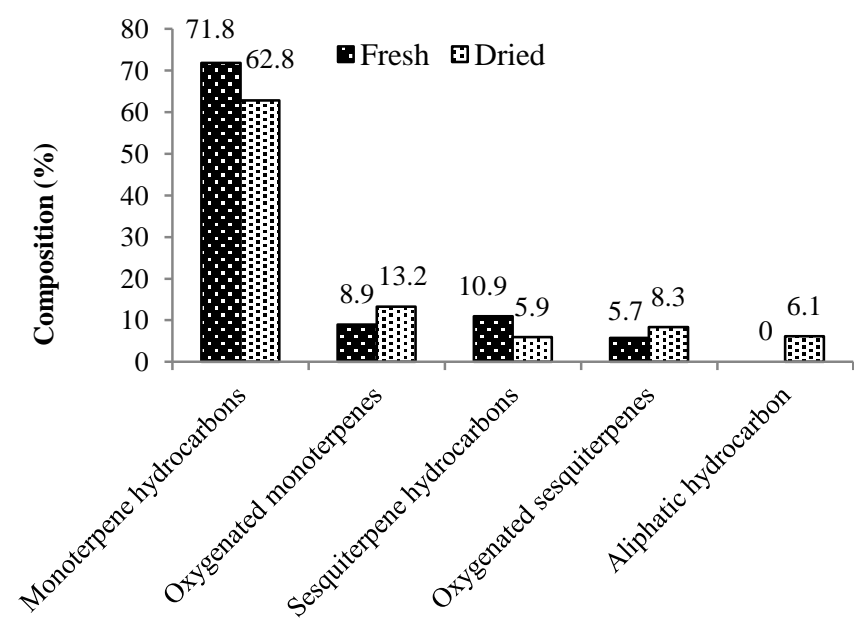

Chemical group

Fig. 1: Percentage concentration of different chemical groups in the essential oils from fresh and dried fruits of Magnolia kobus.

Although higher yield obtained from dried fruits, the concentration of major components such as $\alpha$-pinene, $\beta$-pinene and caryophyllene was comparatively decreased than fresh fruits. Singh et al. (2010) reported that the variations in dried fruits may be due to the absence of aromatic ring and presence of two conjugated double bonds which may undergo oxidation or polymerization very easily. On the other hand, limonene, $\alpha$ terpineol and bornyl acetate contents were increased in the dried samples. Additionally, caryophyllene oxide $(6.0 \%)$, heptadecane (6.1\%), Cymene (1.8\%), terpinen-4-ol (1.1\%), and $\alpha$-thujene $(0.8 \%)$ were detected in the essential oil of dried fruit. Further, $\alpha$ eudesmol $(3.5 \%)$ was detected only in the fresh sample. Azuma et al. (1999) studied the composition of floral scent of M. kobus and identified 36 different volatile components. The major components in the floral scents were linalool and its oxides, limonene, cis and trans-p-ocimene, benzaldehyde, benzyl alcohol, benzyl cyanide, and 2-aminobenzaldehyde. Barros et al. (2012) studied the volatile constituents of the unripe fruits of Magnolia ovata (A. St.-Hil.) Spreng. from two plant populations (A and B). The essential oil from sample A was rich in sesquiterpenes, mainly spathulenol 
(19.3\%), whereas the oil from sample B exhibited a predominance of aliphatic compounds, mainly hexadecanoic acid (52.0\%).

Table 1: Essential oil composition identified from fresh and dried fruits of Magnolia kobus

\begin{tabular}{|c|c|c|c|c|c|}
\hline \multirow[t]{2}{*}{ No. } & \multirow[t]{2}{*}{ Compound name } & \multirow[t]{2}{*}{$\mathbf{R} \mathbf{I}^{\mathbf{a}}$} & \multicolumn{2}{|c|}{ Composition (\%) } & \multirow[t]{2}{*}{ Identification } \\
\hline & & & Fresh & Dried & \\
\hline 1 & $\alpha$-Thujene & 930 & - & 0.8 & MS, RI \\
\hline 2 & $\alpha$-Pinene & 939 & 31.6 & 26.7 & MS, RI \\
\hline 3 & Camphene & 954 & 3.7 & 3.3 & MS, RI \\
\hline 4 & $\beta$-Pinene & 979 & 27.9 & 20.2 & MS, RI \\
\hline 5 & Cymene & 1026 & - & 1.8 & MS, RI \\
\hline 6 & Limonene & 1029 & 8.6 & 10.0 & MS, RI \\
\hline 7 & Eucalyptol & 1031 & 2.9 & 2.9 & MS, RI \\
\hline 8 & Fenchone & 1086 & 1.1 & 1.2 & MS, RI \\
\hline 9 & Terpinen-4-ol & 1177 & - & 1.1 & MS, RI \\
\hline 10 & $\alpha$-Terpineol & 1188 & 3.2 & 4.8 & MS, RI \\
\hline 11 & Bornyl acetate & 1285 & 1.7 & 3.2 & MS, RI \\
\hline 12 & $\beta$-Caryophyllene & 1419 & 8.1 & 3.9 & MS, RI \\
\hline 13 & $\alpha$-Humulene & 1454 & 2.8 & 2.0 & MS, RI \\
\hline 14 & Caryophyllene oxide & 1583 & - & 6.0 & MS, RI \\
\hline 15 & $\alpha$-Eudesmol & 1653 & 3.5 & - & MS, RI \\
\hline 16 & Humulene epoxide II & 1608 & 2.2 & 2.3 & MS, RI \\
\hline 17 & Heptadecane & 1700 & - & 6.1 & MS, RI \\
\hline & \multicolumn{2}{|c|}{ Monoterpene hydrocarbons } & 71.8 & 62.8 & \\
\hline & \multicolumn{2}{|c|}{ Oxygenated monoterpenes } & 8.9 & 13.2 & \\
\hline & \multicolumn{2}{|c|}{ Sesquiterpene hydrocarbons } & 10.9 & 5.9 & \\
\hline & \multicolumn{2}{|c|}{ Oxygenated sesquiterpenes } & 5.7 & 8.3 & \\
\hline & \multicolumn{2}{|l|}{ Aliphatic hydrocarbon } & - & 6.1 & \\
\hline & \multicolumn{2}{|l|}{ Total identified } & 97.3 & 96.3 & \\
\hline & \multicolumn{2}{|l|}{ Oil yield (v/w DW) } & 0.81 & 1.73 & \\
\hline
\end{tabular}

${ }^{a} \mathrm{RI}$ : Retention indices reported in the literature.

Retention indices relative to $\mathrm{C}_{8}-\mathrm{C}_{18} n$-alkanes on the HP-5MS capillary column.

Several authors have reported that the influence of drying methods on yield and composition of essential oil in many aromatic plants. In the present study, results of essential oil composition are in general agreement with previous studies exhibit the drying process produces qualitative and quantitative changes between the fresh and dried samples (Dong et al., 2011; Doymaz, 2011; Tarhan et al., 2011). Based on the drying method and plant species, several changes occur in the yield and composition of essential oil samples (Kubra and Rao, 2012; Calin-Sanchez et al., 2012; Rahimmalek and Goli, 2013). The drying process facilitates the transportation, storage and handling of the plant materials. Further, drying process prevents some important biochemical reactions that can alter organoleptic characteristics of the plants (Díaz-Maroto et al., 2003; Hamrouni-Sellami et al., 2012). Aromatic plants are most sensitive to drying processes that increase the biological deterioration. Therefore, determining an appropriate drying method is very important to obtain high quality essential oil components.

\section{CONCLUSION}

In the present study, the results revealed the identification of 19 different volatile components from fresh and dried fruits of $M$. kobus with $\alpha$-pinene and $\beta$-pinene as major ones. This study indicated that the drying influences the essential oil yield and composition of $M$. kobus fruits. For industrial utilization, standardization of drying method is a fundamental requirement for achieving a high quality product. The studies related to optimization of drying methods for M. kobus fruit are under progress.

\section{ACKNOWLEDGEMENT}

Dr. Kandhasamy Sowndhararajan was financially supported by the Agriculture and Life sciences Research Institute, Kangwon National University, Chuncheon, Republic of Korea.

\section{CONFLICT OF INTEREST}

Authors declare that they have no conflict of interest.

\section{REFERENCES}

Adams RP. 2007. Identification of essential oil components by gas Chromatography/ mass spectrometry. Carol Stream, IL, USA: Allured Publishing Co.

Azuma H, Thien IB, Kawano S. Molecular phylogeny of Magnolia (Magnoliaceae) inferred from cpDNA sequences and evolutionary divergence of the floral scents. Plant Res, 1999; 112: 291306.

Barros LF, Ehrenfried CA, Riva D, Barison A, de Mello-Silva R, Stefanello ME. Essential oil and other constituents from Magnolia ovata fruit. Nat Prod Commun, 2012; 7: 1365-1367.

Calin-sanchez A, Lech K, Szumny A, Figiel A, Carbonllbarrachina AA. Volatile composition of sweet basil essential oil (Ocimum basilicum L.) as affected by drying method. Food Res Int, 2012; 48: 217225.

Diaz-Maroto M, Perez-Coello M, Cabezudo M, Effect of different drying methods on the volatile components of parsley (Petroselinum crispum L.). Eur Food Res Technol, 2002a; 215: 227-230.

Diaz-Maroto MC, Perez-Coello MS, Cabezudo MD. Effect of drying method on the volatiles in bay leaf (Laurus nobilis L.). J Agric Food Chem, 2002b; 50: 4520-4524.

Diaz-Maroto MC, Perez-Coello MS, Vinas MG, Cabezudo MD. Influence of drying on the flavor quality of spearmint (Mentha spicata L.). J Agric Food Chem, 2003; 51: 1265-1269.

Dong J, Xihan M, Zhuorui F, Guo Y. Effects of microwave drying on the contents of functional constituents of Eucommia ulmoides flower tea. Ind Crop Prod, 2011; 34: 1102-1110.

Doymaz I. Drying of thyme (Thymus vulgaris L.) and selection of a suitable thin layer drying model. J. Food Process Pres, 2011; 35: 458465.

Gottsberger G, Silberbauer-Gottsberger I, Seymour RS, Dotterl S. Pollination ecology of Magnolia ovata may explain the overall large flower size of the genus. Flora, 2012; 207: 107-118.

Guerra-Boone L, Alvarez-Roman R, Salazar-Aranda R, TorresCirio A, Rivas-Galindo V.M., Waksman de Torres N, et al. Chemical compositions and antimicrobial and antioxidant activities of the essential oils from Magnolia grandiflora, Chrysactinia mexicana, and Schinus molle found in northeast Mexico. Nat Prod Commun, 2013; 8: 135-138.

Hamrouni-Sellami I, Rahali FZ, Rebey IB, Bourgou S, Limam F, Marzouk B. Total phenolics, flavonoids, and antioxidant activity of sage (Salvia officinalis L.) plants as affected by different drying methods. Food Bioprocess Tech, 2013; 6: 806-817.

Hossain MB, Barry-Ryan C, Martin-Diana AB, Brunton NP. Effect of drying method on the antioxidant capacity of six Lamiaceae herbs. Food Chem, 2010; 123: 85-91.

Jung KY, Kim DS, Oh SR, Park SH, Lee IS, Lee JJ, et al. Magnone $\mathrm{A}$ and $\mathrm{B}$, novel anti-PAF tetrahydrofuran lignans from the flower buds of Magnolia fargesii. J Nat Prod, 1998; 61: 808-811.

Kim GC, Lee SG, Park BS, Kim JY, Song YS, Kim JM, et al. Magnoliae flos induces apoptosis of RBL-2H3 cells via mitochondria and caspase. Int Arch Allergy Imm, 2003; 31: 101-110. 
Kobayashi S, Kobayashi H, Matsuno H, Kimura I, Kimura M. Inhibitory effects of anti-rheumatic drugs containing magnosalin, a compound from 'Shin-i' (Flos magnoliae), on the proliferation of synovial cells in rheumatoid arthritis models. Immunopharmacology, 1998; 39: 139-147.

Kubra IR, Rao LJM. An impression on current developments in the technology, chemistry, and biological activities of ginger (Zingiber officinale Roscoe). Crit Rev Food Sci, 2012; 52: 651-688.

Matsutani H, Shiba T. Tyramine from Magnolia species. Phytochemistry, 1975; 4: 1132-1133.

Rahimmalek M, Goli SAH. Evaluation of six drying treatments with respect to essential oil yield, composition and color characteristics of Thymys daenensis subsp. daenensis. Celak leaves. Ind Crop Prod, 2013; 42: 613-619.

Seo SM, Lee HJ, Lee OK, Jo HJ, Kang HY, Choi DH, et al. Furofuran lignans from the bark of Magnolia kobus. Chem Nat Compd, 2008; 44: 419-423.

Singh G, Kapoor IP, Singh P, de Heluani CS, de Lampasona MP, Catalan CA. Comparative study of chemical composition and antioxidant activity of fresh and dry rhizomes of turmeric (Curcuma longa Linn.). Food Chem Toxicol, 2010; 48: 1026-1031.
Soysal Y. Microwave drying characteristics of parsley. Biosyst Eng, 2004; 89: 167-173.

Tarhan S, Telci I, Tuncay MT, Polatci H. Peppermint drying performance of contact dryer in terms of product quality, energy consumption, and drying duration. Drying Technol, 2011; 29: 642-651.

Venskutonis PR. Effect of drying on the volatile constituents of thyme (Thymus vulgaris L.) and sage (Salvia officinalis L.). Food Chem, 1997; 59: 219-227.

\section{How to cite this article:}

Sowndhararajan K, Cho H, Yu B, Kim S. Comparison of essential oil compositions of fresh and dried fruits of Magnolia kobus DC. J App Pharm Sci, 2016; 6 (04): 146-149. 